\title{
Dexamethasone/Netilmicin Eye Drops and Eye Gel for the Treatment of Ocular Inflammation After Micro-Incisional Vitreoretinal Surgery
}

This article was published in the following Dove Press journal: Clinical Ophthalmology

\author{
Antonio Rapisarda $\mathbb{D}^{1}$ \\ Paolo Arpa ${ }^{2}$ \\ Paolo Maria Fantaguzzi ${ }^{3}$ \\ Francesco Faraldi ${ }^{4}$ \\ Roberto Ratiglia ${ }^{5}$ \\ Stanislao Rizzo ${ }^{6}$ \\ Paola Vaona $\mathbb{( D}^{4}$ \\ Claudio lannacone ${ }^{7}$ \\ Vincenzo Papa ${ }^{8}$ \\ 'Department of Ophthalmology, Azienda \\ Ospedaliera Garibaldi, Catania, Italy; \\ ${ }^{2}$ Department of Ophthalmology, \\ Ospedale San Gerardo, Monza, Italy; \\ ${ }^{3}$ Department of Ophthalmology, \\ Ospedale Morgagni Pierantoni, Forlì, \\ Italy; ${ }^{4}$ Department of Ophthalmology, \\ Presidio Ospedaliero Oftalmico, Torino, \\ Italy; ${ }^{5}$ Department of Ophthalmology, \\ Policlinico Mangiagalli Regina Elena, \\ Milano, Italy; ${ }^{6}$ Department of \\ Ophthalmology, Azienda Ospedaliera \\ Pisana, Pisa, Italy; ${ }^{7}$ Sparc Consulting, \\ Milano, Italy; ${ }^{8}$ Medical Affairs, SIFI SpA, \\ Catania, Italy
}

Correspondence: Vincenzo Papa Medical Affairs SIFI SpA, Via E. Patti 36, Aci S. Antonio, Catania, Italy Email vincenzo.papa@sifigroup.com
Purpose: To evaluate the effect of dexamethasone/netilmicin (dexa/net) fixed combination in the treatment of ocular inflammation after sutureless micro-incisional vitreoretinal surgery (MIVS).

Patients and Methods: This multicenter, open, randomized, active-controlled, parallelgroup, clinical trial was run in 6 sites in Italy. Treatment started the day of surgery and continued 4 times daily for 14 days. Patients were 1:1 randomized to dexa/net (eyedrops solution and eye gel) or dexamethasone/tobramycin (dexa/tobra) eyedrops suspension and ointment. Viscous formulations (gel or ointment) were used alone during the early post-operative phase; afterwards, a combination of eye drops during daytime and viscous formulations at bedtime was adopted. The primary efficacy parameter evaluated was bulbar conjunctival hyperemia. Additional efficacy and safety parameters (palpebral conjunctival hyperemia, anterior chamber flare and cells, symptoms of ocular discomfort and ocular tolerance, adverse events and intraocular pressure) were also evaluated. Control visits were performed at day 1, day 4 and day 14 after surgery; the endpoint of the study was set at $14 \pm 2$ days after surgery.

Results: A complete resolution of bulbar conjunctiva hyperaemia at the study end point was reached in $92.9 \%$ of patients treated with dexa/net and $75.0 \%$ of those treated with dexa/ tobra ( $\mathrm{p}=0.02$, Fisher's exact test). No differences were observed between treatments for other efficacy parameters. Statistically significant differences in favour of dexa/net $(\mathrm{p}<$ 0.0001, ANOVA) were observed for most of subjective tolerance variables examined (blurred vision, foreign body sensation, stickiness, burning) starting day 1 after surgery when only the viscous formulations were used. No increase in intraocular pressure or adverse events was observed during the study.

Conclusion: The combination dexa/net is safe and effective in the treatment of postoperative inflammation following sutureless MIVS. In particular, the use of eye gel formulation is characterized by a great tolerability.

Keywords: vitreoretinal surgery, fixed combination, xanthan gum, tolerability

\section{Introduction}

Epiretinal membranes (ERMs), also commonly known as macular puckers, are avascular, semi-translucent, fibrocellular membranes that form on the inner surface of the retina because of the vitreous pulling away from the retina. They constitute a relatively common condition, occurring in about $7 \%$ of the population, most commonly over the age of $50 .{ }^{1}$ Their symptoms are frequently minimal and can be simply observed. But in some cases, they can result in painless loss of vision and 
metamorphopsia, especially when affecting the macula. In these cases, vitrectomy is the only treatment option. Vitrectomy is one of the most frequently performed ophthalmic surgery; accordingly, approximately 225,000 vitrectomies are performed annually in the United States. ${ }^{2}$ Micro-incisional vitreoretinal surgeries (MIVS) are comprised within this group. They have a very high success rate and low risk of complications, with about 1 in 100 patients developing retinal detachment and 1 in 2000 developing an infection after surgery. ${ }^{3}$ Accordingly, to control post-operative inflammation and to prevent infections, antibiotic and anti-inflammatory topical medications are usually prescribed. The concomitant administration of both agents in a single ophthalmic product may overcome the potential washout effect that may be seen when separate medications are used and may lead to better patient compliance.

Dexamethasone $0.1 \% /$ netilmicin $0.3 \%$ (dexa/net), is a commercially available steroid and antibiotic fixed combination for ophthalmic use (Netildex, SIFI, Italy). Both ingredients are widely known in ophthalmology and have well-documented efficacy and safety. ${ }^{4-7}$ Several clinical trials have been conducted with dexa/net eye drops in patients with either external ocular inflammation or who underwent cataract extraction. ${ }^{8-10}$ The product was consequently approved in several countries for the treatment of inflammatory ocular conditions with, or at risk of, bacterial infections. A new formulation of dexa/net has been recently developed. This formulation is a preservativefree (single-dose container) eye gel with the same qualitative and quantitative composition of the eye drop solution. This eye gel contains xanthan gum as viscosity enhancer, an excipient which does not interfere with the antimicrobial and anti-inflammatory activities of the product. A recent study showed that dexa/net eye gel was retained on the ocular surface longer than dexa/net ophthalmic solution, suggesting, therefore, that the use of eye gel could extend the time between instillations and allow a decrease in administration frequency. ${ }^{11}$

In the present study, we have selected sutureless MIVS to evaluate the efficacy and safety of dexa/net eye gel and ophthalmic solution. Since dexamethasone 0.1\%/tobramycin $0.3 \%$ (dexa/tobra) is considered the gold standard of the pharmaceutical category of steroid/antibiotic fixed combinations, this product (formulated as ophthalmic suspension and eye ointment) has been used as comparator.

\section{Patients and Methods \\ Oversight}

The study protocol was approved by the institutional review board at each research center. Participating sites: Azienda Ospedaliera Garibaldi Catania (Italy), Ospedale San Gerardo Monza (Italy), Ospedale Morgagni Pierantoni Forlì (Italy), Presidio Ospedaliero Oftalmico Torino (Italy), Policlinico Mangiagalli Regina Elena Milano (Italy), Azienda Ospedaliera Pisana Pisa (Italy). All participants provided written informed consent and the study was conducted according to the Declaration of Helsinki and Good Clinical Practice guidelines. This trial is registered at the European Union Clinical Trials Register, with EudraCT no. 2008-005082-64

\section{Trial Design}

This study was a multicenter, open, randomized, activecontrolled, parallel-group, explorative clinical trial conducted in 6 sites in Italy. The main objective of the study was to investigate the therapeutic efficacy of dexa/net (ophthalmic solution and eye gel) in the control and treatment of post-surgical ocular inflammation following sutureless micro-incisional (23-25 gauge, as per international standards) vitreoretinal surgery in adult patients with ERMs. A control group of patients was treated with dexa/tobra (eye ointment and eye drops).

\section{Participants}

A total of 103 patients (age between 30 and 74 years old) with ERMs having to undergo 23-25-gauge vitreoretinal surgery were enrolled in the study. Subjects were excluded from the study if they had: 1) recurrent anterior/posterior segment inflammation of unknown etiology or history of inflammation and/or ocular trauma in the previous year; 2) concomitant systemic and ocular pathologies (diabetes, ocular infections, glaucoma, ocular hypertension, severe dry-eye); 3) indication for combined vitreoretinal and cataract extraction surgery; 4) previous vitreoretinal surgeries adopting a buckling procedure, laser or cryogenic retinopexy; 5) cataract surgery in the previous 3 months; 6) any ocular surgery in the previous year; 7) intraocular pressure $>22 \mathrm{mmHg}$; 8) use of any antibiotic, antihistamine, decongestant, steroid or non-steroidal antiinflammatory agents within 14 days prior to study entry; 9) use of any ocular medications other than artificial tears; 10) known or suspected allergy to ophthalmic preservatives, aminoglycosides and steroids; 11) use of intra-operative intravitreal administration of triamcinolone acetonide, gas tamponade or suture. 


\section{Interventions}

At baseline, patients were randomized 1:1 to dexa/net or dexa/ tobra using a computer-generated list of random numbers. The different packaging of the investigational and reference products did not allow a double-masked approach. Treatment started the day of surgery (day 0) and continued 4 times a day for $14 \pm 2$ days. Patients were treated either with dexa/ net ophthalmic solution plus eye gel or dexa/tobra ophthalmic suspension plus eye ointment. Viscous formulations (eye gel and eye ointment) were used alone during the early postoperative phase; afterwards, according to clinical practice, a combination of eye drops during daytime and viscous formulations at bedtime was adopted. A schematic description of the treatment schedule is summarized in Table 1. Control visits were scheduled 1, 4 and 14 days (primary end point) after surgery.

\section{Outcomes}

Conjunctival hyperemia (bulbar and palpebral) was evaluated using a 0 to 3 rating scale, as previously described; ${ }^{12}$ bulbar conjunctival hyperemia was selected as primary efficacy parameter of the study. Anterior chamber flare and cells were rated from 0 to 3 according to the SUN Group grading scheme. ${ }^{13}$ Symptoms of ocular discomfort (pain, photophobia, itching) and symptoms of ocular tolerance of products (blurred vision, foreign body sensation, stickiness, burning, tearing, global subjective tolerance) were evaluated with a 0 (none) to 100 (severe) Visual Analogue Rating Scale (VARS). ${ }^{14}$ Adverse events and intraocular pressure (IOP) were the main safety parameters analysed.

\section{Statistics}

Statistical analysis was performed by SPARC Consulting (Milan, Italy) using the SAS system version 9.2. Continuous variables were summarized by descriptive statistics (number of cases, mean, standard deviation, median, minimum and maximum). Categorical variables were summarized using counts of patients and percentages. For categorical endpoints, differences between treatment arms were tested using the Chi-square test or Fisher's exact test, where applicable, at a 5\% significance level. Two-sided $95 \%$ confidence intervals for proportions were also calculated. According to the exploratory nature of the study, all statistical tests were regarded as descriptive only.

\section{Study Populations}

The following population subsets were analyzed:

- Safety: subjects who were operated, randomized and received at least one dose of study medication, regardless of any protocol deviation.

- Full Analysis (FA): subjects in the safety subset without major protocol deviations and for whom at least the score for bulbar conjunctival hyperemia was available at Visit 4 (14 \pm 2 days).

- Per Protocol (PP): subjects in the FA population without any relevant protocol deviations

\section{Primary Efficacy Parameter}

Data were analyzed for both FA and PP populations with descriptive statistics. The primary efficacy parameter of the study was the percentage of patients showing a bulbar conjunctival hyperemia score equal to 0 (absence of

Table I Treatment Schedule

\begin{tabular}{|l|l|l|l|}
\hline \multicolumn{2}{|l|}{} & \multicolumn{2}{l|}{ Study Treatments } \\
\hline PERIOD I & $\begin{array}{l}\text { Dexamethasone/netilmicin } \\
\text { eye gel }\end{array}$ & $\begin{array}{l}\text { Dexamethasone/tobramycin } \\
\text { eye ointment }\end{array}$ \\
\hline Dose & & I drop & I application $(0.5-I \mathrm{~cm})$ \\
\hline Schedule & $\begin{array}{l}\text { Day 0 } \\
\text { Days I-3 }\end{array}$ & $\begin{array}{l}\text { I time daily } \\
4 \text { times daily }\end{array}$ & $\begin{array}{l}\text { I time daily } \\
4 \text { times daily }\end{array}$ \\
\hline PERIOD II & $\begin{array}{l}\text { Dexamethasone/netilmicin } \\
\text { eye gel and eye drops }\end{array}$ & $\begin{array}{l}\text { Dexamethasone/tobramycin } \\
\text { eye-ointment and eye drops }\end{array}$ \\
\hline Dose & I drop [eye drops, eye gel] & $\begin{array}{l}\text { one drop [eye drops] } \\
\text { one application [eye ointment] }\end{array}$ \\
\hline Schedule & Days 4-I4 & $\begin{array}{l}\text { I drop of the eye-drops 3 times daily } \\
\text { I drop of the eye gel at bedtime }\end{array}$ & $\begin{array}{l}\text { I drop of the eye-drops 3 times daily } \\
\text { I application of the eye ointment at bed-time }\end{array}$ \\
\hline
\end{tabular}


hyperemia, normal vascular pattern) at the end of the study (day 14), such percentage was compared between two groups of treatment by means of a Fisher's exact test. Moreover, bulbar conjunctival hyperemia was compared within each group of treatment at day 14 in comparison to the first day after surgery (day 1) using the McNemar's test.

\section{Additional Parameters}

All data related to the additional efficacy parameters were summarized for the FA population with descriptive statistics whereas data related to safety parameters were summarized for the Safety population.

Individual scores for palpebral conjunctival hyperemia, anterior chamber flare and anterior chamber cells were compared between treatment groups using the Wilcoxon ranksum test. In addition, scores of each visit were compared to those of the first day after surgery (day 1) within each treatment group using the Wilcoxon test for paired observations. For symptoms, a summary statistic was prepared and data were compared between and within treatment groups using the repeated analysis of variance (ANOVA). IOP values were summarized by treatment and visit. Adverse events were encoded using the MedDRA dictionary version 14 and listed according to the ICH guidelines.

\section{Sample Size}

Since this study had mainly a descriptive aim, no statistical based sample size calculation was done assuming that a sample size of 50 patients per group was assumed to be enough for the purpose of the study.

\section{Results}

One hundred three Caucasian patients (60 females, 43 males; median age 65 years) who underwent MIVS without application of suture were enrolled and randomized: 50 subjects were treated with dexa/net and 53 with dexa/ tobra. All patients completed the study. No leakages from sclerotomies were recorded in the clinical report forms. The compliance to the study protocol was good. All randomized patients have been included in the safety population. The FA population includes 90 patients whereas the PP population includes 79 patients. The study flow diagram is shown in Figure 1.

The day after surgery (day 1 ), the most evident sign of ocular inflammation was a hyperemia of the conjunctiva.

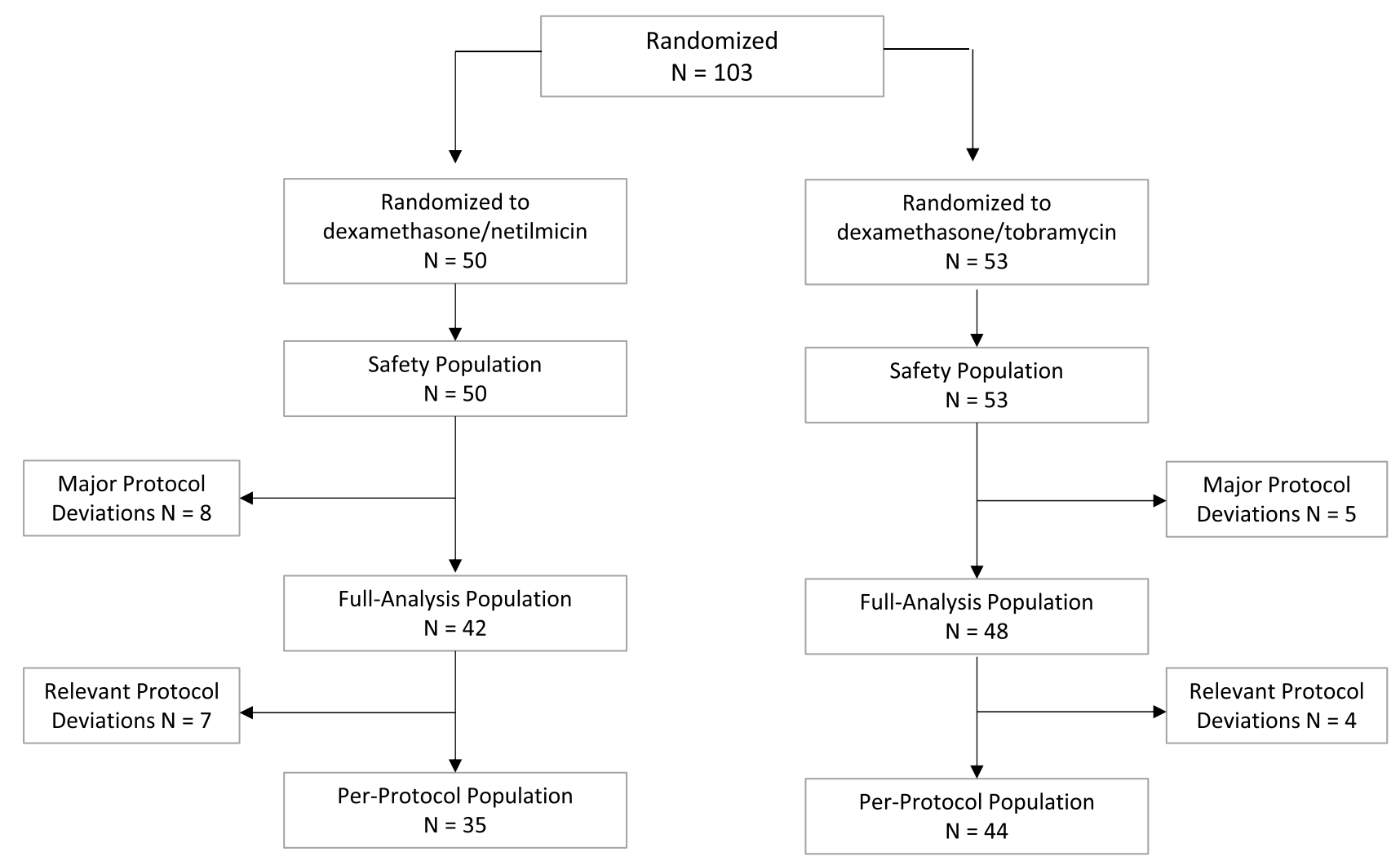

Figure I Patients disposition. 
Hyperemia of bulbar conjunctiva (primary efficacy parameter) was present (score $>0$ ) in $74 \%$ of patients, whereas hyperemia of palpebral conjunctiva was present (score $>0$ ) in $40 \%$ of patients. On the contrary, anterior chamber inflammation was detected (flare or cells score $>0$ ) only in few patients ( $6 \%$ for flare and $4 \%$ for cells).

In both treatment arms, an effective and progressive decrease of the severity of bulbar conjunctival hyperemia was observed ( $<<0.0001, \mathrm{McNemar}$ test) (data not shown). At the study end point (day 14), a complete resolution of bulbar conjunctival hyperemia ( almost all patients $(92.9 \%)$ treated with dexa/net and only in $75.0 \%$ of those treated with dexa/tobra (FA subset). This difference (Д $=17.9 ; 95 \%$ Confidence interval $=32.4$ to 3.3 ) was statistically significant $(\mathrm{p}=0.02$, Fisher Exact Test) (Figure 2). Similar results were observed also in the PP population (97.1\% vs $75.0 \%$; Д $=22.1$; 95\% Confidence interval $=36.1$ to $8.2 ; \mathrm{p}=0.01)$. A progressive improvement was observed also for palpebral conjunctival hyperemia ( $p<0.0001$, Wilcoxon test), pain, photophobia and itching $(\mathrm{p}<0.0001$, ANOVA), but not for anterior chamber flare and anterior chamber cells $(\mathrm{p}=0.250$, Wilcoxon test). No differences were observed between the two groups of treatment for any of these parameters (data not shown).

The local tolerance of viscous pharmaceutical forms administered during the study (i.e. "eye gel" and "eye ointment") was also evaluated. The extent of blurred vision, foreign body sensation, stickiness, burning and tearing after administration was assessed by VARS scales. A consistent statistically significant difference in favor of

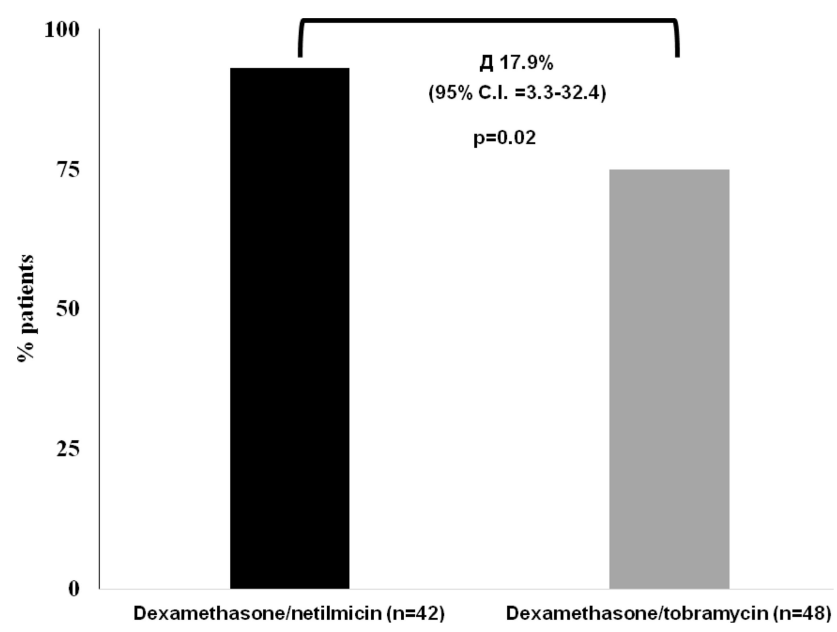

Figure 2 Effects of treatment on hyperemia of the conjunctiva. Percentage of patients with a complete resolution of conjunctival hyperemia $($ score $=0)$ at the end of the study (day 14 after surgery). A Fisher Exact Test was performed between the two groups of treatment. eye gel was observed for all parameters of tolerance, with the exception of tearing (Table 2). Accordingly, the global subjective tolerance of treatments assessed at the end of the study preferred, for both formulations, dexa/net over dexa/tobra ( $p=0.0142$ eye gel vs eye ointment; $p=0.0226$ eye drops solution vs eye drops suspension). Only 1 adverse event (choroidal detachment) was recorded during the study. The event occurred in the dexa/tobra group, it was not serious, not treatment related and did not require any therapy or hospitalization. No post-surgical ocular infection occurred during the study. Regarding IOP levels, no significant elevation of the pressure was observed in the study in any treatment arm; mean change from screening visit to the end visit (day 14) was $-0.33 \pm 2.35$ and 0.30 $\pm 2.28 \mathrm{mmHg}$, in the dexa/net and dexa/tobra arms, respectively.

\section{Discussion}

Epiretinal membrane is relatively common retinal conditions in which patients may be asymptomatic or report mild to severe visual dysfunction. Vitrectomy surgery is often indicated in patients who are affected with a decrease in visual acuity, metamorphopsia, double vision, or difficulty using their eyes together. ${ }^{15}$ In such cases, an effective post-operative treatment requires suppression of ocular surface inflammation and prevention of bacterial infections and, therefore, a combination of steroid and antibiotic treatment is preferred.

Dexa/net is a fixed steroid/antibiotic ophthalmic combination containing a well-known corticosteroid (dexamethasone) and a last-generation aminoglycoside (netilmicin). Dexa/net has several advantages over similar products, mainly related to the antibiotic component and the formulation. Regarding the antibiotic component, netilmicin has a wide spectrum antimicrobial activity and a low level of resistance covering also methicillin-resistant (MR) strains (as MR S. Aureus and MR Coagulase negative Staphylococci) $)^{7,16,17}$ Overall, the susceptibility of the most common ocular microorganisms to netilmicin is higher than tobramycin and comparable to last-generation quinolones. ${ }^{16-18}$ Netilmicin has also a negligible toxicity for human conjunctival and corneal epithelial cells. ${ }^{19}$ The formulation advantage of dexa/net is related to the watersolubility of both active principles (dexamethasone phosphate and netilmicin sulphate). Accordingly, dexa/net is a formulated as ready-to-use and comfortable preservativefree, eye drops solution and eye gel, rather than suspension. ${ }^{9}$ 
Table 2 Symptoms of Local Tolerance

\begin{tabular}{|c|c|c|c|c|}
\hline & $\begin{array}{l}\text { Dexamethasone/ } \\
\text { Tobramycin }(n=48)\end{array}$ & $\begin{array}{l}\text { Dexamethasone/ } \\
\text { Netilmicin }(n=42)\end{array}$ & $\begin{array}{l}\text { P-value Between Groups } \\
\text { (ANOVA) }\end{array}$ & $\begin{array}{l}\text { P-value Within Groups } \\
\text { (ANOVA) }\end{array}$ \\
\hline \multicolumn{5}{|c|}{ Blurred vision } \\
\hline Day I & $39.48 \pm 26.17$ & $26.38 \pm 18.18$ & 0.0012 & $<0.0001$ \\
\hline Day 4 & $32.73 \pm 20.49$ & $|9.85 \pm| 4.8 \mid$ & & \\
\hline Day 14 & $24.58 \pm 17.89$ & $18.86 \pm 13.34$ & & \\
\hline \multicolumn{5}{|c|}{ Foreign body sensation } \\
\hline Day I & $33.25 \pm 22.94$ & $27.75 \pm 21.95$ & 0.0023 & $<0.0001$ \\
\hline Day 4 & $28.74 \pm 20.49$ & $16.41 \pm 13.50$ & & \\
\hline Day 14 & $18.85 \pm 15.25$ & $11.04 \pm 7.06$ & & \\
\hline \multicolumn{5}{|c|}{ Stickiness } \\
\hline Day I & $32.14 \pm 19.62$ & $25.60 \pm 18.14$ & 0.0145 & $<0.000$ I \\
\hline Day 4 & $25.85 \pm 18.46$ & $17.27 \pm 12.25$ & & \\
\hline Day 14 & $17.79 \pm 13.16$ & $14.18 \pm 9.26$ & & \\
\hline \multicolumn{5}{|c|}{ Burning } \\
\hline Day I & $32.79 \pm 22.14$ & $27.33 \pm 22.75$ & 0.025 & $<0.0001$ \\
\hline Day 4 & $24.33 \pm 17.00$ & $16.67 \pm 14.97$ & & \\
\hline Day 14 & $16.29 \pm 13.47$ & $10.89 \pm 8.95$ & & \\
\hline \multicolumn{5}{|c|}{ Tearing } \\
\hline Day I & $30.41 \pm 18.20$ & $28.20 \pm|9.2|$ & 0.4568 & $<0.0001$ \\
\hline Day 4 & $22.94 \pm 16.20$ & $18.40 \pm 15.62$ & & \\
\hline Day 14 & $14.76 \pm 9.82$ & $|5.4| \pm \mid 4.82$ & & \\
\hline
\end{tabular}

Note: Data are expressed as mm VARS (mean $\pm \mathrm{SD}$ ).

Abbreviation: VARS, visual analogue rating scale.

In the present study, we investigated efficacy, safety and local tolerance of dexa/net eye gel in the management of the inflammation after sutureless MIVS. Dexa/ net eye gel was compared to dexa/tobra eye ointment. These viscous formulations were used as standalone treatment during the early post-operative phase (3 days); afterwards, according to a local clinical practice, a combination of eye drops during daytime and viscous formulations at bedtime was adopted. The rationale for use of viscous formulation in the immediate postoperative time is related to the attempt to increase ocular contact time of topically administered drug. ${ }^{11}$ Data presented herein suggest that dexa/net, given as proposed, is effective in controlling post-surgical inflammation after sutureless MIVS. These findings are consistent with data obtained in the treatment of external ocular inflammation $^{9}$ and in the management of ocular inflammation subsequent to cataract surgery. ${ }^{8,10}$ Despite the open design of the study, we believe that these data may give helpful information for vitreoretinal surgeons in the "real-life" management of MIVS. In this study, signs and symptoms of ocular inflammation (except for anterior chamber flare and cells) were effectively reduced during the follow-up, regardless the assigned treatment. However, a significant difference between groups was observed for bulbar conjunctival inflammation (primary efficacy parameter of the study). At end of the study, the percentage of patients with a resolution of inflammation of the bulbar conjunctiva in the group treated with dexa/ net was significantly higher than that treated with dexa/ tobra $(92.9 \%$ vs $75.0 \%, p=0.02)$. The reason of this difference is unknown. Dexamethasone alcohol (present in dexa/tobra) has a higher anti-inflammatory activity than dexamethasone phosphate (present in dexa/net); despite that, in the presence of ocular inflammation, dexamethasone phosphate is greater absorbed equilibrating its relative lower potency. ${ }^{5}$ Therefore, the expected anti-inflammatory effect of two products should be comparable. In addition, patients treated with dexa/net experienced a significantly lower intensity of symptoms 
compared to patients treated with dexa/tobra. The instillation of a ready-to-use eye drops solution (rather than suspension) and the presence of xanthan gum in the dexa/ net eye gel formulation may confer to the product a peculiar behavior leading to a greater local tolerability. Finally, no significant safety issues occurred during the entire study.

In conclusion, dexa/net can effectively reduce postsurgical ocular inflammation following sutureless microincisional vitreoretinal surgery. Particularly, the eye gel formulation can give additional benefits to patients in term of local tolerability. Due to the limited number of patients exposed, additional studies with more patients are needed to confirm these findings.

\section{Data Sharing Statement}

The dataset generated and analyzed of the study is available from the corresponding author upon request.

\section{Acknowledgments}

Authors thank Laura C. Collada Ali for providing medical writing support in accordance with Good Publication Practice (GPP3) guidelines and with the International Committee of Medical Editors (ICMJE) recommendations.

\section{Disclosure}

V Papa is an employee of SIFI SpA, manufacturer and supplier of Netildex. Current affiliation for S Rizzo is Università Cattolica Sacro Cuore Roma (Italy). C Iannacone reports personal fees from LB Research during the conduct of the study. A Rapisarda, P Arpa, PM Fantaguzzi, R Ratiglia and $\mathrm{P}$ Vaona are retirees. The authors report no other conflicts of interest in this work.

\section{References}

1. Kean Theng Oh JHD. Epiretinal Membrane; 2018. https://emedicine. medscape.com/article/1223882-overview\#a4. accessed 25 July 2019.

2. Reddy RK, Lalezary M, Kim SJ, et al. Prospective Retinal and Optic Nerve Vitrectomy Evaluation (PROVE) study: findings at 3 months. Clin Ophthalmol. 2013;7:1761-1769.
3. Sophie J, Bakri A, Capone A, et al. The American Society of Retina Specialists, https://www.asrs.org/patients/retinal-diseases/19/epiret inal-membranes. accessed 25 July 2019.

4. Nielsen RH. The use of dexamethasone in ophthalmologic steroid therapy: a preliminary report. Arch Ophthalmol. 1959;62 (438-444): 15 .

5. Leibowitz HM, Kupferman A. Antiinflammatory medications. Int Ophthalmol Clin. 1980;20:117-134.

6. Gordon DM. Use of dexamethasone in eye disease. JAMA. 1960;172:311-312.

7. Papa V, Aragona P, Scuder AC, et al. Treatment of Acute Bacterial Conjunctivitis With Topical Netilmicin. Cornea. 2002;21(1):43-47.

8. Russo S, Papa V, Di Bella A, et al. Dexamethasone-netilmicin: a new ophthalmic steroid-antibiotic combination. Efficacy and safety after cataract surgery. Eye. 2007;21:58-64.

9. Faraldi F, Papa V, Rasà D, et al. Netilmicin/dexamethasone fixed combination in the treatment of conjunctival inflammation. Clin Ophthalmol. 2013;7:1239-1244.

10. Pianini V, Passani A, Rossi GC, et al. Efficacy and safety of netilmycin/dexamethasone preservative-free and tobramycin/dexamethasone-preserved fixed combination in patients after cataract surgery. J Ocular Pharm Therapeutics. 2010;26:617-621.

11. Gagliano C, Papa V, Amato R, et al. Measurement of the Retention Time of Different Ophthalmic Formulations with Ultrahigh-Resolution Optical Coherence Tomography. Curr Eye Res. 2018;43:499-502.

12. Papa V, Milazzo G, Santocono M, et al. Naproxen ophthalmic solution to manage inflammation after phacoemulsification. $J$ Cataract Refract Surg. 2002;28:321-327.

13. Standardization Of Uveitis Nomenclature (Sun) Working Group. Fluoroquinolones Against Ophthalmic Pathogens from Europe in 2010-2011. Am J Ophthalmol. 2005;140:509-516.

14. Price DD, McGrath P, Rafii A, et al. The validation of visual analogue scales as ratio scale measures for chronic and experimental pain. Pain. 1983;17:45-56.

15. American Academy of Ophthalmology Retina/Vitreous Panel. Preferred Practice Pattern ${ }^{\hat{a}}$ Guidelines. Age-Related Macular Degeneration. San Francisco, CA; 2015. Available at www.aao.org/ppp.

16. Blanco AR, Roccaro AS, Spoto CG, et al. Susceptibility of Methicillin-resistant Staphylococci Clinical ISolates to Netilmicin and Other Antibiotics Commonly Used in Ophthalmic Therapy. Curr Eye Res. 2013;38(8):811-816.

17. Sanfilippo CM, Morrissey I, Janes R, et al. Surveillance of the Activity of Aminoglycosides and Fluoroquinolones Against Ophthalmic Pathogens from Europe in 2010-2011. Curr Eye Res. 2015;41(5):581-589.

18. Papa V, Blanco AR, Santocono M. Ocular flora and their antibiotic susceptibility in patients having cataract surgery in Italy. $J$ Cataract Refract Surg. 2016;42(9):1312-1317.

19. Papa V, Leonardi A, Getuli C, et al. Effect of Ofloxacin and Netilmicin on Human Corneal and Conjunctival Cells In Vitro. J Ocular Pharm Therapeutics. 2003;19(3):535-545.
Clinical Ophthalmology

\section{Publish your work in this journal}

Clinical Ophthalmology is an international, peer-reviewed journal covering all subspecialties within ophthalmology. Key topics include: Optometry; Visual science; Pharmacology and drug therapy in eye diseases; Basic Sciences; Primary and Secondary eye care; Patient Safety and Quality of Care Improvements. This journal is indexed on PubMed
Central and CAS, and is the official journal of The Society of Clinical Ophthalmology (SCO). The manuscript management system is completely online and includes a very quick and fair peer-review system, which is all easy to use. Visit http://www.dovepress.com/ testimonials.php to read real quotes from published authors. 